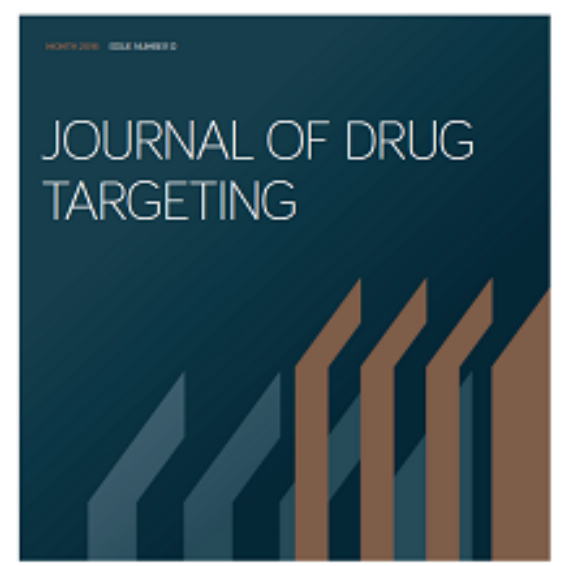

\title{
Design, Stability and Efficacy of a New Targeting Peptide for Nanoparticle Drug Delivery to SH-SY5Y Neuroblastoma Cells
}

\begin{tabular}{|r|l|}
\hline Journal: & Journal of Drug Targeting \\
\hline Manuscript ID & JDT-2018-OR-0264.R2 \\
\hline Manuscript Type: & Original Paper \\
\hline Author: & 19-Nov-2018 \\
\hline Complete List of Authors: & $\begin{array}{l}\text { Huey, Rachel; Ulster University } \\
\text { Rathbone, Dan; Aston University } \\
\text { McCarron, Paul; University of Ulster } \\
\text { Hawthorne, Susan; University of Ulster, School of Pharmacy \& } \\
\text { Pharmaceutical Science }\end{array}$ \\
\hline Keywords: & peptide targeting, nanoparticle, targeted drug delivery, neural cell, RDP \\
\hline & \\
\hline
\end{tabular}

\section{SCHOLARONE ${ }^{m}$ \\ Manuscripts}




\section{Design, Stability and Efficacy of a New Targeting Peptide for Nanoparticulate Drug Delivery to SH-SY5Y Neuroblastoma Cells}

Rachel Hueya , Dan Rathbone ${ }^{\mathrm{b}}$, Paul McCarron ${ }^{\mathrm{a}} \&$ Susan Hawthorne ${ }^{\mathrm{a} *}$

a School of Pharmacy \& Pharmaceutical Sciences, Ulster University, Coleraine, UK.

b Aston Pharmacy School, Aston University, Aston Triangle, Birmingham, UK.

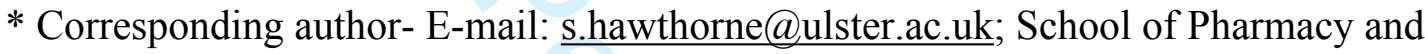
Pharmaceutical Sciences, Ulster University, Coleraine, Northern Ireland BT52 1SA, UK 


\begin{abstract}
In recent years, rabies virus-derived peptide (RDP) has shown promise as a specific neural cell targeting ligand, however stability of the peptide in human serum was unknown. Herein, we report the molecular modelling and design of an optimised peptide sequence based on interactions of RDP with the $\alpha 7$ subunit of the nicotinic acetylcholine receptor (nAChR). The new sequence, named DAS, designed around a 5-mer sequence which demonstrated optimal nAChR binding in silico, showed greatly improved stability for up to 8 hours in human serum in comparison to RDP, which degraded within 2 hours at $37^{\circ} \mathrm{C}$. In vitro analysis using SH-SY5Y neuroblastoma cells showed that DAS-conjugated nanoparticles containing the cytotoxic drug doxorubicin (DAS-Dox-NP) displayed significantly enhanced cytotoxicity compared with untargeted doxorubicin-loaded nanoparticles (Dox-NP). DASDox-NP had no significant effect on non-neural cell types, confirming its neural-specific targeting properties.
\end{abstract}

This is the first time that In this manuscript, we report the design and testing of an optimised peptide ligand, conjugated to a nanoparticulate delivery vehicle and specifically targeted to neural cells,, has been reported. Future impact of an innovative targeting peptide ligand combining the ability to selectively identify the target and facilitate cellular internalisation could enable the successful treatment of many neural cell disorders.

Key words: peptide targeting, nanoparticle, drug delivery, neural cell, RDP 


\begin{abstract}
Abbreviations
DAS - newly designed targeting peptide
\end{abstract}

DOX- doxorubicin

DOX-NP - unlabelled doxorubicin-loaded nanoparticles

$\alpha 7 \mathrm{nAChR}$ - nicotinic acetylcholine receptor alpha 7 subunit

NP- nanoparticles

PLGA- poly (lactic-co-glycolic) acid

RDP- rabies virus derived peptide

RDP-DOX-NP - RDP-labelled doxorubicin-loaded nanoparticles

DAS-DOX-NP - DAS-labelled doxorubicin-loaded nanoparticles sc-DAS - scrambled version of the newly designed targeting peptide sc-DAS-DOX-NP - scrambled DAS-labelled doxorubicin-loaded nanoparticles 


\section{Introduction}

Specific targeting of therapeutics is a growing area of research for a number of different disease states. The benefits of this over conventional drug delivery are numerous, including improved bioavailability of the drug at the target organ, reduction of unwanted side effects and smaller dosages required for therapeutic effect. Cell penetrating peptides (CPPs) can greatly enhance the intracellular uptake of conjugated cargo across biological membranes in a non-invasive, non-disruptive manner. However, due to lack of tissue specificity, CPPs such as TAT (transactivating transcriptional activator) peptide, penetratin and polyarginine are not as efficient when aiming to deliver expensive or toxic drugs [1]. One group of diseases which are difficult to treat and may benefit from targeted delivery methods are neural cell disorders such as neuroblastoma [2-4] and neurosarcoma [5].

Neural cell-specific peptide targeting ligands have been explored in the past decade to deliver therapeutic agents in animal studies with success [6-10]. Many promising neural cell-specific targeting peptides take advantage of native receptors, transporters or enzymes to deliver therapeutic cargoes. Derivatives from natural neurotoxic agents have been utilised due to their highly efficient transport abilities to nervous systems, such as tetanus toxin fragment $\mathrm{C}$ [11], neurotropic virus glycoproteins and fragments of snake, scorpion and bee venoms [10]. Thus far, promising results with these ligands are still surrounded with concerns of immune reactions and true specificity for neural cells only. Kumar et al. [6] first showed that a derivative of rabies virus glycoprotein (RVG), RVG-29, utilised nicotinic acetylcholine receptor (nAChR) transport to safely and non-invasively deliver siRNA to neuro-2a cells and mouse brain. Following this success, derivatives of RVG have since been utilised to take advantage of this property for drug delivery to the CNS to treat a range of brain disorders [12-14]. 
RVG found in the rabies virus envelope, is responsible for viral entry into the nervous system [15]. Rabies virus-derived peptide (RDP) is a 39-amino acid derivative of RVG, which has shown early success as a neural cell-targeting ligand both in vitro and in vivo [16-19]. In previous work [20], we reported that RDP is dependent upon interaction with the nAChR and activity was inhibited by blocking the homomeric $\alpha 7$ subtype of this receptor, commonly found throughout the nervous systems. An obstacle in the development of many peptide targeting ligands is the issue of serum instability due to proteolysis, hence breakdown of the peptide upon systemic administration. This is particularly true for larger sequences of amino acids, which may be more susceptible to enzymatic degradation in vivo. Fu et al. [16] reported that the approximate in vivo half-life of an RDP fusion protein in mice is only one hour. The stability of RDP ligand alone in human serum has not yet been reported, however given its relatively large size it could be subject to stability issues in future studies.

In this study, we report for the first time the molecular modelling, design and development of an optimised neural cell-targeting sequence, which we have termed DAS, based on interactions of RDP with the neural $\alpha 7 \mathrm{nAChR}$ subunit. Furthermore, we report the enhanced stability of DAS in human serum compared to RDP and highlight its ability to specifically target neural cells with concomitant release of active nanoparticulate payloads.

\section{Materials and Methods}

\section{Materials}

Resomer $^{\circledR}$ RG 502 H, Poly(D,L-lactide-co-glycolide)-PLGA, acid terminated (MW 7,00017,000), dichloromethane (DCM), poly(vinyl) alcohol (PVA) 87-89\% hydrolysed- MW 
85,000-124,000, MES hydrate, 1-ethyl-3-(3-dimethylaminopropyl)-carbodiimide (EDC), Nhydroxysuccinimide (NHS), trichloroacetic acid (TCA), human serum from male AB plasma (USA origin), $\alpha$-cyano-4-hydroxycinnamic acid (CHCA) matrix, 3-[4,5-dimethylthiazol-2yl]-2,5 diphenyl tetrazolium bromide (MTT), hexamethonium and mecamylamine were all purchased from Sigma-Aldrich (UK). RDP, DAS and scrambled DAS (sc-DAS) peptides were synthesised by GL Biochem (Shanghai) Ltd. Nicotinic acetylcholine receptor- $\alpha 7$ antibody was purchased from Santa Cruz Biotechnology, Inc. (USA). Doxorubicin hydrochloride was obtained from VWR International (Pennsylvania, USA). Tissue culture reagents and media were purchased from Gibco $\AA /$ Life Technologies. Human cancer cell lines, SH-SY5Y (human neuroblastoma) and HeLa (human cervical cancer), were cultured in RPMI 1640 medium as were the normal CHO (Chinese hamster ovary) cell line. MDA-MB231 (human breast cancer) cells were cultured in DMEM medium. Both RPMI 1640 and DMEM media were supplemented with $10 \%$ foetal bovine serum and $1 \%$ penicillinstreptomycin $\left(5,000 \mathrm{U} \mathrm{ml}^{-1 / 5}, 000 \mu \mathrm{g} \mathrm{ml}^{-1}\right)$. All other chemicals were of analytical grade.

\section{Design of novel targeting peptide}

\section{Step 1 Protein-ligand docking}

Potential interactions between RDP and the $\alpha 7$ homomeric nAChR were explored, using $\alpha$ subunit residues $173-204$ as a starting point in this study. Original rabies virus glycoprotein (RVG) is reported to bind to these residues of the $\alpha 1 \mathrm{nAChR}$ subunit found at the neuromuscular junction (NMJ), hence facilitating the entry of the rabies virus into the nervous system $[21,22]$. The coordinates of the neuronal nAChR $\alpha 7$ subunit, acetylcholinebinding protein were obtained from the Protein Databank entry 3SQ6, chain A [23]. This was imported into CACHe Worksystem Pro (version 7.5.0.85; Fujitsu Ltd). Hydrogen atoms 
were added using the default settings in line with presumed protonation states for ionisable amino acid side-chains. The positions of the added hydrogen atoms were optimised by locking the coordinates of all the non-hydrogen atoms and subjecting the system to a molecular mechanics (MM2) geometry optimisation. The 30-mer of RDP, KSVRTWNEIIPSKGCLRVGGRCHPHVNGGG, was divided into all possible contiguous ten amino acid fragments (residues $1-10 ; 2-11 ; 3-12$ etc.) and each docked four times, using CACHe Worksystem Pro, into the prepared protein structure from 3SQ6 where the potential active site was defined as residues $173-204$. The amino acid side-chains in the defined active site were allowed to be flexible as were all rotatable bonds in the 10 -mer proteins. The genetic algorithm settings for the docking protocol included population size 50, maximum generations 3000 , crossover rate 0.8 , mutation rate 0.2 and convergence when the RMSD population fitness was less than 1 .

\section{Step 2 Molecular dynamics simulations}

The input files for molecular dynamics simulations of the docked protein-ligand complexes were prepared using the Antechamber module of the AMBER Tools package (Version 14) [24], implementing the ff14SB force field. Disulphide bonds were enforced between the receptor residue pairs $125 \& 138$ and $186 \& 187$. The system was neutralised by addition of sodium ions and then solvated within a truncated octahedron of TIP3P water molecules extending $8 \AA$ from the surface of the protein. Using the Amber 14 molecular dynamics package CUDA version [25-27], the system was energy-minimised for 2,000 cycles using a non-bonded cut-off of $12 \AA$ and then heated under constant volume to $300 \mathrm{~K}$ over 25 ps under Langevin dynamics (time step $=1 \mathrm{fs}$ ). The heating was continued at $300 \mathrm{~K}$ for a specified period under constant pressure also using Langevin dynamics (SHAKE on, time 
step $=2 \mathrm{fs}$ ) using the Particle-Mesh-Ewald (PME) method to treat the long range electrostatic interactions with a $12 \AA$ non-bonded cut-off.

\section{Step 3 Peptide design}

Residues of interest from RDP (GCLRV) were identified from the work carried out in section 2.2.1- 2.2.2 and were subsequently incorporated into the design of a new peptide. A widely used flexible linking sequence -GGGGS- was subsequently added to the GCLRV sequence as a spacer in the design of a new peptide [28], to allow freedom of movement once conjugated to PLGA NP. Finally, two glycine residues followed by an arginine tail consisting of 6 alternating L- and D- arginine residues -GGRrRrRr- were also added to the sequence for enhanced stability and resistance to metabolic processes [29]. The new D-argininecontaining 18-amino acid sequence, which we have termed DAS, was $\mathrm{NH}_{2}$ GGGGSGCLRVGGRrRrRr-COOH.

\section{Serum stability of RDP and DAS peptides}

Peptide stability testing in human serum was carried out according to a previously detailed method [30]. Briefly, human serum was diluted to $25 \%$ with phosphate buffered saline (PBS) and subsequently centrifuged at $18809 \mathrm{~g}$ for 10 minutes to remove lipids, before incubating at $37^{\circ} \mathrm{C}$. RDP and newly derived peptide, DAS, were prepared so that final serum peptide concentration was $10 \mu \mathrm{M}$ prior to incubation at $37^{\circ} \mathrm{C}$. A $200 \mu \mathrm{L}$ aliquot was removed from each serum-peptide mixture at various time points and reacted with $40 \mu \mathrm{L}$ of $15 \%$ TCA for 15 minutes at $4^{\circ} \mathrm{C}$ to remove larger serum proteins. The collected samples were centrifuged at $18809 \mathrm{~g}$ to remove precipitated serum proteins for 10 minutes and supernatant collected for storage at $-20^{\circ} \mathrm{C}$. Samples were analysed by MALDI-TOF mass spectrometry (PerSeptive 
Biosystems Voyager-DE Biospectrometer, Herefordshire UK). A $10 \mu \mathrm{L}$ aliquot of serum sample was mixed with $10 \mu \mathrm{L}$ of CHCA matrix (10 mg/mL fully dissolved), $1.5 \mu \mathrm{L}$ of which was used for analysis. The mass/charge ratio $(\mathrm{m} / \mathrm{z})$ was plotted against relative abundance.

\section{Preparation of nanoparticles and conjugation of peptide to nanoparticles}

Doxorubicin-loaded PLGA nanoparticles (Dox-NP) were prepared by a double emulsion technique and characterised according to methods previously described by this group [20]. FITC-Dextran-loaded PLGA nanoparticles (FITC-NP) for confocal fluorescence imaging were also prepared and characterized using the method previously described in [20] using 4 mg of FITC-Dextran per $100 \mathrm{mg}$ of PLGA polymer. Entrapment efficiency (EE) of FITCDextran and doxorubicin in NP was determined using fluorescence spectroscopy (excitation $485 \mathrm{~nm}$, emission $520 \mathrm{~nm}$ ) and UV-Vis absorbance (480 nm) respectively, on a FLUOstar Omega microwell plate reader (BMG Labtech, Germany).

$$
E E=\frac{\text { Mass of drug in NP }}{\text { Mass of drug added }} \times 100 \%
$$

Peptides were conjugated to nanoparticles according to methods previously described by this group [20].

$\underline{\text { In vitro assays }}$

Initial studies suggested that the presence of serum in the cell-based assay medium had minimal influence on the results of DAS-conjugated NP treatment (see Appendix 3). Therefore all assays were carried out in serum free medium to minimise possible interference associated with serum proteins in in vitro assays. 


\section{In vitro cellular uptake study}

Cellular uptake of FITC-NP preparations were evaluated in SH-SY5Y and HeLa cell lines using a Leica SP5 confocal microscope (x 63,000 magnification). Cells were seeded onto 13 $\mathrm{mm}$ glass coverslips at a concentration of $1 \times 10^{5}$ cells $/ \mathrm{mL}(500 \mu \mathrm{L})$ and cultured in complete RPMI media at $37^{\circ} \mathrm{C} / 5 \% \mathrm{CO}_{2}$ overnight. All existing media was aspirated and the ceells were treated with $1 \mathrm{mg} / \mathrm{mL}(500 \mu \mathrm{L})$ of either FITC-NP, RDP-FITC NP or DAS-FITC NP $\underline{\text { in }}$ serum free media (SFM) for 24 hours whilst incubating at $37^{\circ} \mathrm{C} / 5 \% \mathrm{CO}_{2}$. Prior to imagining, all cells including controls were treated with $75 \mathrm{nM}$ Lysotracker red in serum free media (SFM) for 30 minutes to visualise lysosomes in cells and track potential co-localisation with NP along the cellular internalisation pathway. FITC fluorescence emission was collected between 510- $550 \mathrm{~nm}$ (excitation wavelength $490 \mathrm{~nm}$ ). Lysotracker emission was collected separately between 590-650 $\mathrm{nm}$ (excitation wavelength $580 \mathrm{~nm}$ ).

\section{In vitro cytotoxicity study}

SH-SY5Y cells were plated out at a concentration of $1 \times 10^{5}$ cells $/ \mathrm{mL}$ (96 well plate) in complete RPMI media and incubated at $37^{\circ} \mathrm{C} / 5 \% \mathrm{CO}_{2}$ for 16 hours. A range of DAS DoxNP concentrations were initially tested to determine the most effective concentration to use for subsequent assays. All existing media was aspirated and the cells were then treated with $100 \mu \mathrm{L}$ of serum free media (SFM) and either $60 \mu \mathrm{L}$ of a $4 \mathrm{mg} / \mathrm{mL}$ NP suspension (final concentration $1.5 \mathrm{mg} / \mathrm{mL}$ ) or an equivalent concentration of free peptide. Control wells were treated with serum-free media only. Cell viability was assessed after incubating for 24 hours $\left(37^{\circ} \mathrm{C} / 5 \% \mathrm{CO}_{2}\right)$, using an MTT assay. To calculate cell viability, $25 \mu \mathrm{L}$ of MTT $(5 \mathrm{mg} / \mathrm{ml})$ in PBS was added to each well on top of media and incubated at $37^{\circ} \mathrm{C} / 5 \% \mathrm{CO}_{2}$ for 2 hours. After this, all media was aspirated and cells solubilised with $70 \mu \mathrm{L}$ of DMSO per well. UVVis absorbance was read at $570 \mathrm{~nm}$ and cell viability calculated. To assess targeting specificity to neural cells, NP treatment was also added to non-neural cell lines CHO, HeLa and MDA-MB-231 according to the same protocol. The cytotoxic effect of a scrambled 
version of DAS $\left(\mathrm{NH}_{2}\right.$-RVGGCSGGGGGLRrRrRr-COOH) conjugated to Dox-NP (scDASDox NP) was also assessed in SH-SY5Y cells.

We demonstrated previously that RDP function could be blocked with nAChR inhibitors [20]. To determine whether nAChR antagonists would affect the activity of DAS, SH-SY5Y cells were first preincubated for 30 minutes with either $1 \mathrm{mM}$ hexamethonium (competitive), $1 \mathrm{mM}$ mecamylamine (non-competitive) or anti- AChR $\alpha 7$ antibody (1:100 dilution), all in serum-free medium, prior to addition of Dox-NP or DAS-Dox NP, using the method described above.

\section{Statistical Analysis}

All results reported were statistically analysed using an unpaired t-test. A p value of $<0.05$ was considered statistically significant.

\section{Results}

\section{Design of novel targeting peptide}

A model of the receptor was built using the X-ray crystal structure coordinates from the Protein Databank, entry 3SQ6, chain A [23]. For the purposes of the docking experiments the active site was defined as residues 173 - 204. The 30-mer RDP peptide was divided into all possible contiguous ten amino acid fragments (residues 1-10;2-11;3-12 etc.) and docked into the receptor. The 10-mer fragments were allowed full rotational flexibility as were the side-chains of the amino acids in the receptor active site. Each fragment was docked four 
times using a genetic algorithm protocol and the complexes were scored using potential of mean force (PMF: given in $\mathrm{kcal} / \mathrm{mol}$ ). Since the genetic algorithm uses an initial random number seed, the best (lowest energy) result only is reported for each 10-mer fragment in Table 1. [Table 1 near here]. The 10-mer fragment that gave the best binding enthalpy score (PMF energy) comprised residues 9-18 (IIPSKGCLRV). The best-scoring complex from this fragment was subjected to molecular dynamics in explicit water for $100 \mathrm{~ns}$. After the first 50 ns of simulation it was noticed that not all of the 10-mer was interacting with the receptor. Residues 9 - 12 (IIPS) in particular were positioned on average orthogonal to the receptor surface and engaged with water molecules. A snapshot at $92 \mathrm{~ns}$ is shown in Figure 1 [Figure 1 near here]. .

Consequently, the initial receptor IIPSKGCLRV complex was cut down to a version containing residues 14-18 (GCLRV) and this complex was subjected to molecular dynamics in explicit water for $100 \mathrm{~ns}$. After a settling period of approximately $60 \mathrm{~ns}$, the GCLRV fragment adopted a fairly stable conformation (RMSD plot shown in Appendix 1) on the surface of the receptor with each amino acid, except for the N-terminal glycine, making hydrogen bonding interactions. Hydrophobic interactions with the receptor were also observed for the leucine and the valine residues in this fragment. A two-dimensional view of the receptor-GCLRV interactions can be found in Appendix 2. A new peptide (DAS) incorporating the GCLRV fragment from RDP was designed accordingly, consisting of 18 amino acids (GGGGSGCLRVGGRrRrRr) as described earlier in this report.

\section{Serum stability of RDP and DAS peptides}

RDP and DAS were incubated in $25 \%$ human serum at $37^{\circ} \mathrm{C}$ and then analysed by MALDITOF mass spectrometry to determine stability (Figure 2) [Figure 2 near here]. . RDP with no 
prior incubation (Figure 2B) gave rise to a peak consistent with its molecular weight of 4.6 $\mathrm{kDa}$. Upon incubation in serum for 2 hours intact RDP was no longer detectable, however a new signal was detected between 2.7-3.2 kDa, most likely to be RDP breakdown fragments (Figure 2C). A minimal trace of RDP remained in Figure 2D, suggesting RDP and its degradation products had continued to degrade over 8 hours. Fully intact DAS expectedly gave rise to a peak at around $1.9 \mathrm{kDa}$ indicated in Figure 2E, prior to incubation at $37^{\circ} \mathrm{C}$. After 2 hours of incubation, approximately $60 \%$ of the signal remained, as shown in Figure 2F. After 8 hours in serum, a small amount of intact DAS remained as indicated (Figure 2G). Over the time course observed the new 18-mer peptide, DAS, was more resistant to degradation by serum proteases than RDP.

\section{Characterisation of NP preparations}

Particle size, zeta potential, drug content and peptide conjugation efficiency of the formulations are shown in Table 2. PLGA NP were successfully loaded with either cytotoxic doxorubicin or FITC-Dextran with entrapment efficiencies of $64 \%$ and $77 \%$ respectively. [Table 2 near here].

\section{In vitro cellular uptake}

Visualisation of FITC-NP uptake by confocal fluorescence microscopy (Figure 3) demonstrates the ability of both RDP and DAS to preferentially target SH-SY5Y neural cells and promote cellular uptake compared to the untargeted FITC-NP [Figure 3 near here]. . In contrast, detected fluorescence signal was low in Hela cells and no notable difference in cellular uptake was observed between all formulations, indicating that RDP and DAS do not function as targeting peptides in this non-neural cell line. Furthermore, the signal detected by 


\begin{abstract}
Lysotracker red indicates that there may be co-localisation of lysosomes and internalised FITC-NP in SH-SY5Y cells.
\end{abstract}

\title{
In vitro cytotoxicity study
}

\section{The $\mathrm{IC}_{50}$ of DAS Dox-NP was calculated to be $0.9 \mathrm{mg} / \mathrm{mL}$ (Figure 4) [Figure 4 near here].}

Figure 54A shows the effect of DAS conjugation to Dox-NP in SH-SY5Y neural cells. Treatment with DAS-Dox NP caused a significant enhancement in SH-SY5Y cytotoxicity, as cell viability decreased to $60.0 \%( \pm 6.0 \% \mathrm{SD})$ compared with $82.7 \%( \pm 4.0 \% \mathrm{SD})$ when treated with untargeted Dox-NP. Figure $\underline{54}$ A also shows that neither free RDP nor free DAS peptides caused any significant decrease in cell viability. In addition, when a scrambled version of the DAS peptide was conjugated to Dox NP (sc-DAS-Dox NP), there was no significant decrease in cell viability compared to untargeted Dox-NP treatment [Figure $\underline{5} 4$ near here]. .

Figure $54 \mathrm{~B}$ shows the effect of preincubating SH-SY5Y cells with the nAChR antagonists hexamethonium, mecamylamine and anti- AChR $\alpha 7$ antibody. Pretreatment with all of the antagonists inhibits the cytotoxic effects of DAS-DOX-NP. These results suggest that DAS is facilitating uptake of cytotoxic NP through mechanisms involving the nAChR.

The effects of DAS-DOX-NP on the non-neural cell lines HeLa, MDA-MB-231 and CHO are shown in Figure 65 [Figure 65 near here]. . The cell viabilities for the normal, non-neural CHO cells and the cancer cell lines HeLa and MDA-MB-231 ranged narrowly from $62 \%$ 75\% between all NP-treated groups. In the neural cell line SHSY-5Y however, both RDP and DAS promote susceptibility of the cells to the cytotoxic effects of Dox-NP showing a statistically significant decrease in cell viability for both RDP-Dox NP $(59.7 \% \pm 4.7 \% \mathrm{SD})$ 
and DAS-Dox NP $(62.0 \% \pm 9.8 \% \mathrm{SD})$ formulations compared to the untargeted Dox-NP $(75.0 \% \pm 7.1 \% \mathrm{SD})$

\section{Discussion}

$\mathrm{RDP}$ is a peptide with a molecular weight of $4.6 \mathrm{kDa}$ and, as such, its size may make it prone to proteolysis by serum proteases, which would severely limit its in vivo targeting ability and application. Therefore, design of a smaller and more proteolytically resistant peptide, which retains the sequence essential for binding to the $\mathrm{nAChR}$, could be very beneficial. In earlier work, we reported that RDP requires the nAChR for function [20]. In this current work we modelled for interactions between RDP and the $\alpha 7 \mathrm{nAChR}$ subunit (which is specific to neural nAChR) [31] and uncovered a 5-amino acid section of the RDP sequence, -GCLRV-, which displays strong interactions with the $\alpha 7 \mathrm{nAChR}$ subunit and has potential for development as a new targeting sequence. The addition of poly-arginine residues to a peptide has shown to promote water solubility and confer highly effective cell penetrating properties to a conjugated cargo whilst prolonging circulation time [29,32], therefore we included six arginine residues at the $\mathrm{C}$ terminal of the new peptide and included half of them as the protease-resistant $\mathrm{D}$ amino acid. In doing this, the whole peptide should be less vulnerable to serum proteases and negatively charged plasma proteins, an effect which Liu et al. reported as similar to pegylation [32]. We also added the linker sequence-GGGGS- to the $\mathrm{N}$ terminal of the peptide, as described in the methods section, to allow free movement of the peptide once conjugated to the NP. 
The reported use of RDP as a neural cell-specific targeting ligand both in vitro and in vivo has been a promising step towards facilitating delivery of therapeutics to neural cells [16-19]. However, there have been no reports on the stability of RDP in serum, with a previous stability study looking at RDP-conjugated nanoparticles concentrating on the stability of the payload and not the targeting peptide [33].

In this report, we have shown for the first time that RDP breaks down when incubated with human serum at $37^{\circ} \mathrm{C}$ within 2 hours (Figure $2 \mathrm{C}$ ). Although this may be long enough to demonstrate an effect in vivo, it would be desirable to optimise the peptide sequence to make it less prone to enzymatic degradation in serum. If serum half-life could be extended then potential in vivo dosing would be lower and less frequent, which is preferable when utilising expensive or toxic therapeutic payloads. Our findings show that the new DAS peptide displays a considerable improvement in stability characteristics compared to RDP, with mass spectrometry analysis detecting intact DAS peptide up to 8 hours after incubation in human serum at $37^{\circ} \mathrm{C}$ (Figure $2 \mathrm{G}$ ). D-amino acids, such as the D-arginine residues incorporated into DAS, have been used to improve the proteolytic resistance of peptides successfully within the area of drug delivery due to their ability to avoid quick metabolism [29,34]. There have also been many reports in the literature on the use of D-amino acid substitutions to promote serum stability of targeting peptides which aligns with the results reported here [35-39].

In a previous publication, we demonstrated the use of RDP as a targeting ligand which enhanced the uptake of a conjugated nanoparticulate payload to induce cytotoxic effects in SH-SY5Y cells [20]. These findings are further supported by the confocal fluorescence images presented in Figure 3, which show RDP and DAS both facilitate NP uptake into neural cells specifically. It has been suggested by Fu et al. [17], that the cellular uptake mechanism of RDP may involve energy-dependent internalisation pathways such as clathrindependent endocytosis. Indeed, observations of co-localisation between RDP and DAS 
conjugates with lysosomes in our findings support this idea (Figure 3). In addition, we have also demonstrated that, like RDP, DAS significantly enhances cytotoxicity of Dox-NP in SHSY5Y cells compared to untargeted DOX-NP and both free RDP and DAS peptides, which are non-toxic (Figure 5 4A). When a scrambled version of DAS was conjugated to Dox NP (sc-DAS-Dox NP), there was no enhancement in cytotoxicity compared to untargeted DoxNP treatment (Figure 54 A) demonstrating the necessity to retain the original -GCLRVtargeting sequence derived from RDP.

We also reported previously that nAChR antagonists prevented RDP action in SH-SY5Y cells [20] and the same inhibitors were employed to observe their effect on DAS peptide action. Mecamylamine, hexamethonium and antibody against $\alpha 7$ subunit of homomeric neuronal nAChR were able to block the effects of DAS-DOX-NP confirming that DAS does indeed bind to neuronal nAChR in the same way as RDP (Figure $\underline{5} 4 \mathrm{~B}$ ).

The results displayed in Figure 65 confirm the specific action of DAS as a neural celltargeting ligand as it had no significant effect in three non-neural cell lines (HeLa, MDAMB-231 and $\mathrm{CHO})$.

In conclusion, the results described herein demonstrate that using molecular modelling and peptide design we have created a novel, bespoke neural cell nAChR targeting peptide, which we have termed DAS. This peptide displays an enhancement in serum stability whilst retaining neural cell specificity, and aids efficient cellular uptake and release of nanoparticle payloads. This targeted delivery system has potential for use in delivering therapeutics in a more specific manner to neural cells. 


\section{Acknowledgements}

Special thanks to the Dowager Countess Eleanor Peel Trust and the Department of Employment and Learning (DEL) Northern Ireland for their financial support of this work.

\section{Declarations of interest}

Authors have no conflict of interest.

\section{Funding}

The Dowager Countess Eleanor Peel Trust [grant number- MBE/12005960.1] and the Department of Employment and Learning (DEL) Northern Ireland funded this work. Neither funding source was involved in the preparation or submission of this manuscript.

\section{References}

[1] Malhotra M, Prakash S. Targeted drug delivery across blood-brain-barrier using cell penetrating peptides tagged nanoparticles. Current Nanoscience. 2011;7(1):81-93.

[2] Louis C, Shohet J. Neuroblastoma: molecular pathogenesis and therapy. Ann. Rev. Med. $2014 ; 66 ; 49-63$ 
[3] Whittle S, Smith V, Doherty E, Zhao S, McCarty S, Zage P. Overview and recent advances in the treatment of neuroblastoma. Expert Rev. Anticancer Ther. 2017;17:369-386

[4] Coughlan D, Gianferante M, Lynch C, Stevens J, Harlan L. Treatment and survival of childhood neuroblastoma: Evidence from a population-based study in the United States. Pediatric Hematology and Oncology. 2017;34:320-330

[5] Zehou O, Fabre E, Zelek L, Sbidian E, Ortonne N, Banu E, Wolkenstein P, ValeyrieAllanore L. Chemotherapy for the treatment of malignant peripheral nerve sheath tumors in neurofibromatosis 1: a 10-year institutional review. Orphanet Journal of Rare Diseases. $2013 ; 8: 127-133$

[6] Kumar P, Wu H, McBride JL, Jung K, Kim, MH, Davidson BL, Lee SK, Shankar P, Manjunath N. Transvascular delivery of small interfering RNA to the central nervous system. Nature. 2007;448(7149):39-43.

[7] Kwon EJ, Lasiene J, Jacobson BE, Park I, Horner PJ, Pun SH. Targeted nonviral delivery vehicles to neural progenitor cells in the mouse subventricular zone. Biomaterials. 2010;31(8):2417-2424.

[8] Zhang B, Sun X, Mei H, Wang Y, Liao Z, Chen J, Zhang Q, Hu Y, Pang Z, Jiang X. LDLR-mediated peptide-22-conjugated nanoparticles for dual-targeting therapy of brain glioma. Biomaterials. 2013;34(36):9171-9182.

[9] Gao Y, Wang Z, Zhang J, Zhang Y, Huo H, Wang T, Jiang T, Wang S. RVG-peptidelinked trimethylated chitosan for delivery of siRNA to the brain. Biomacromolecules. 2014;15(3):1010-1018. 
[10] Soddu E, Rassu G, Giunchedi P, Sarmento B, Gavini E. From naturally-occurring neurotoxic agents to CNS shuttles or drug delivery. European Journal of Pharmaceutical Sciences. 2015;74:63-76.

[11] Toivonen JM, Olivan S, Osta R. Tetanus toxin C-fragment: The courier and the cure? Toxins. 2010;2(11):2622-2644.

[12] Liu Y, Huang R, Han L, Ke W, Shao K, Ye L, Lou J, Jiang C. Brain-targeting gene delivery and cellular internalization mechanisms for modified rabies virus glycoprotein RVG29 nanoparticles. Biomaterials. 2009;30(25):4195-4202.

[13] Chen W, Zhan C, Gu B, Meng Q, Wang H, Lu W, Hou H. Targeted brain delivery of itraconazole via RVG29 anchored nanoparticles. J Drug Target. 2011;19(3):228-234.

[14] Son S, Hwang DW, Singha K, Jeong JH, Park TG, Lee DS, Kim WJ. RVG peptide tethered bioreducible polyethylenimine for gene delivery to brain. J Controlled Release. 2011;155(1):18-25.

[15] Yan XZ, Mohankumar PS, Dietzschold B, Schnell MJ, Fu ZF. The rabies virus glycoprotein determines the distribution of different rabies virus strains in the brain. J Neurovirol. 2002;8(4):345-352.

[16] Fu A, Wang Y, Zhan L, Zhou . Targeted delivery of proteins into the central nervous system mediated by rabies virus glycoprotein-derived peptide. Pharm Res. 2012;29(6):15621569.

[17] Fu A, Zhao Z, Gao F, Zhang M. Cellular uptake mechanism and therapeutic utility of a novel peptide in targeted-delivery of proteins into neuronal cells. Pharm Res. 2013;30(8):2108-2117. 
[18] Fu A, Zhang M, Gao F, Xu X, Chen Z. A novel peptide delivers plasmids across bloodbrain barrier into neuronal cells as a single-component transfer vector. Plos One. 2013;8(3):e59642.

[19] Wu, J., Zhang, E. and Fu, A. A novel cell-permeable RDP-p53 fusion protein for specific inhibition on the growth of cancerous neural cells. Drug delivery. 2016, 23 (7), 24642470.

[20] Huey R, O’Hagan B, McCarron P, Hawthorne S. Targeted drug delivery system to neural cells utilizes the nicotinic acetylcholine receptor. Int J Pharm. 2017;525(1):12-20.

[21] Lentz TL. Rabies virus binding to an acetylcholine receptor alpha-subunit peptide. J Mol Recognit. 1990;3(2):82-88.

[22] Gastka M, Horvath J, Lentz TL. Rabies virus binding to the nicotinic acetylcholine receptor alpha subunit demonstrated by virus overlay protein binding assay. J Gen Virol. $1996 ; 77: 2437-2440$.

[23] Li SX, Huang S, Bren N, Noridomi K, Dellisanti CD, Sine SM, Chen L. Ligandbinding domain of an $\alpha 7$-nicotinic receptor chimera and its complex with agonist. Nature Neuroscience. 2011;14:1253-1259.

[24] Case DA, Cheatham TE, Darden T, Gohlke H, Luo R, Merz KM, Onufriev A, Simmerling C, Wang B, Woods RJ. The Amber biomolecular simulation programs. J Chem Theory Comput. 2005;26:1668-1688.

[25] Salomon-Ferrer R, Goetz AW, Poole D, Le Grand S, Walker RC. Routine microsecond molecular dynamics simulations with AMBER - Part II: Particle Mesh Ewald. J Chem Theory Comput. 2013;9:3878-3888. 
[26] Goetz AW, Williamson, MJ, Xu D, Poole D, Le Grand S, Walker RC. Routine microsecond molecular dynamics simulations with AMBER on GPUs. 1. Generalized born. J Chem Theory Comput. 2012;8:1542-1555.

[27] Le Grand S, Goetz AW, Walker RC. SPFP: Speed without compromise - a mixed precision model for GPU accelerated molecular dynamics simulations. Comput Phys Commun. 2013;184:374-380.

[28] Chen X, Zaro JL, Shen W. Fusion protein linkers: Property, design and functionality. Adv Drug Deliv Rev. 2013;65(10):1357-1369.

[29] Wender PA, Galliher WC, Goun EA, Jones LR, Pillow TH. The design of guanidiniumrich transporters and their internalization mechanisms. Adv Drug Deliv Rev. 2008;60(45):452-472.

[30] Nguyen LT, Chau JK, Perry NA, de Boer L, Zaat SAJ, Vogel HJ. Serum stabilities of short tryptophan-and arginine-rich antimicrobial peptide analogs. Plos One. 2010;5(9):e12684.

[31]- Gotti C, Zoli M, Clementi F. Brain nicotinic acetylcholine receptors: Native subtypes and their relevance. Trends Pharmacol Sci. 2006;27(9):482-491.

[32] Liu Y, Lu Z, Mei L, Yu Q, Tai X, Wang Y, Shi K, Zhang Z, He Q. Tandem peptide based on structural modification of poly-arginine for enhancing tumor targeting efficiency and therapeutic effect. Acs Applied Materials \& Interfaces. 2017;9(3):2083-2092.

[33] Gao Y, Wang Z, Zhang J, Zhang Y, Huo H, Wang T, Jiang T, Wang S. RVG-peptidelinked trimethylated chitosan for delivery of siRNA to the brain. Biomacromolecules. 2014;15(3):1010-1018. 
[34] Purkayastha N, Eyer K, Robinson T, Dittrich PS, Beck AK, Seebach D, Kolesinska B, Cadalbert R. Enantiomeric and diastereoisomeric (mixed) L/D-octaarginine derivatives - A simple way of modulating the properties of cell-penetrating peptides. Chemistry \& Biodiversity. 2013;10(7):1165-1184.

[35] Soudy R, Gill A, Sprules T, Lavasanifar A, Kaur K. Proteolytically stable cancer targeting peptides with high affinity for breast cancer cells. J Med Chem. 2011;54(21):75237534.

[36] Wang S, Noberini R, Stebbins JL, Das S, Zhang Z, Wu B, Mitra S, Billet S, Fernandez A, Bhowmick NA, Kitada S, Pasquale EB, Fisher PB, Pellecchia M. Targeted delivery of paclitaxel to EphA2-expressing cancer cells. Clinical Cancer Research. 2013;19(1):128-137.

[37] Di Grazia A, Cappiello F, Cohen H, Casciaro B, Luca V, Pini A, Di YP, Shai Y, Mangoni ML. D-amino acids incorporation in the frog skin-derived peptide esculentin-1a(121)NH2 is beneficial for its multiple functions. Amino Acids. 2015;47(12):2505-2519.

[38] Ngambenjawong C, Gustafson HH, Pineda JM, Kacherovsky NA, Cieslewicz M, Pun SH. Serum stability and affinity optimization of an M2 macrophage-targeting peptide (M2pep). Theranostics. 2016;6(9):1403-1414.

[39] Meng Z, Luan L, Kang Z, Feng S, Meng Q, Liu K. Histidine-enriched multifunctional peptide vectors with enhanced cellular uptake and endosomal escape for gene delivery. Journal of Materials Chemistry B. 2017;5(1):74-84. 
Table 1. PMF docking scores for the 10-mer fragments ranked in order of score.

\begin{tabular}{cc}
\hline Fragment & $\begin{array}{c}\text { PMF Docking } \\
\text { Score } \\
\text { (kcal/mol) }\end{array}$ \\
\hline 9_18 & -815.10 \\
17_26 & -804.66 \\
10_19 & -791.05 \\
12_21 & -779.10 \\
16_25 & -767.22 \\
11_20 & -763.91 \\
14_23 & -754.99 \\
8_17 & -753.55 \\
4_13 & -752.98 \\
21_30 & -742.21 \\
1_10 & -728.43 \\
18_27 & -728.35 \\
7_16 & -723.68 \\
13_22 & -723.66 \\
2_11 & -721.83 \\
6_15 & -712.65 \\
19_28 & -703.93 \\
20_29 & -702.34 \\
5_14 & -693.11 \\
3_12 & -682.99 \\
15_24 & -639.01 \\
\hline & \\
\hline & \\
\hline
\end{tabular}


Table 2. PLGA nanoparticle characterisation parameters.

\begin{tabular}{|c|c|c|c|c|c|}
\hline NP sample & $\operatorname{Size}^{a}($ d.nm$)$ & $\mathbf{Z P} \mathbf{P}^{a}(\mathbf{m V})$ & $\begin{array}{c}\mathrm{DC}^{b} \\
(\boldsymbol{\mu g} / \mathbf{m g})\end{array}$ & $\operatorname{RDP}^{c}(\mu \mathrm{g} / \mathrm{mg})$ & $\begin{array}{c}\mathrm{DAS}^{d} \\
(\mu \mathrm{g} / \mathrm{mg})\end{array}$ \\
\hline Dox-NP & $242.7 \pm 18.6$ & $-14.6 \pm 1.3$ & 12.8 & 53.6 & 23.2 \\
\hline FITC-NP & $286.5 \pm 11.3$ & $-10.3 \pm 1.0$ & 30.8 & 97.2 & 43.9 \\
\hline \multicolumn{6}{|c|}{$\begin{array}{l}{ }^{a} \text { Size and zeta potential (ZP) reported as average of three measurements } \pm \text { standard } \\
\text { deviation. }{ }^{b} \mathrm{DC}=\text { drug content per } 1 \mathrm{mg} \text { of NP based on entrapment efficiencies of } 64 \% \\
\text { (Dox) and } 77 \% \text { (FITC); }{ }^{c} \text { RDP content per } 1 \mathrm{mg} \text { of NP based on conjugation efficiency of } \\
54 \% \text { to Dox-NP and } 73 \% \text { to FITC-NP. }{ }^{d} \text { DAS content per } 1 \mathrm{mg} \text { of NP based on conjugation } \\
\text { efficiency of } 58 \% \text { to Dox-NP and } 88 \% \text { to FITC-NP. }\end{array}$} \\
\hline
\end{tabular}




\section{Appendix 1}

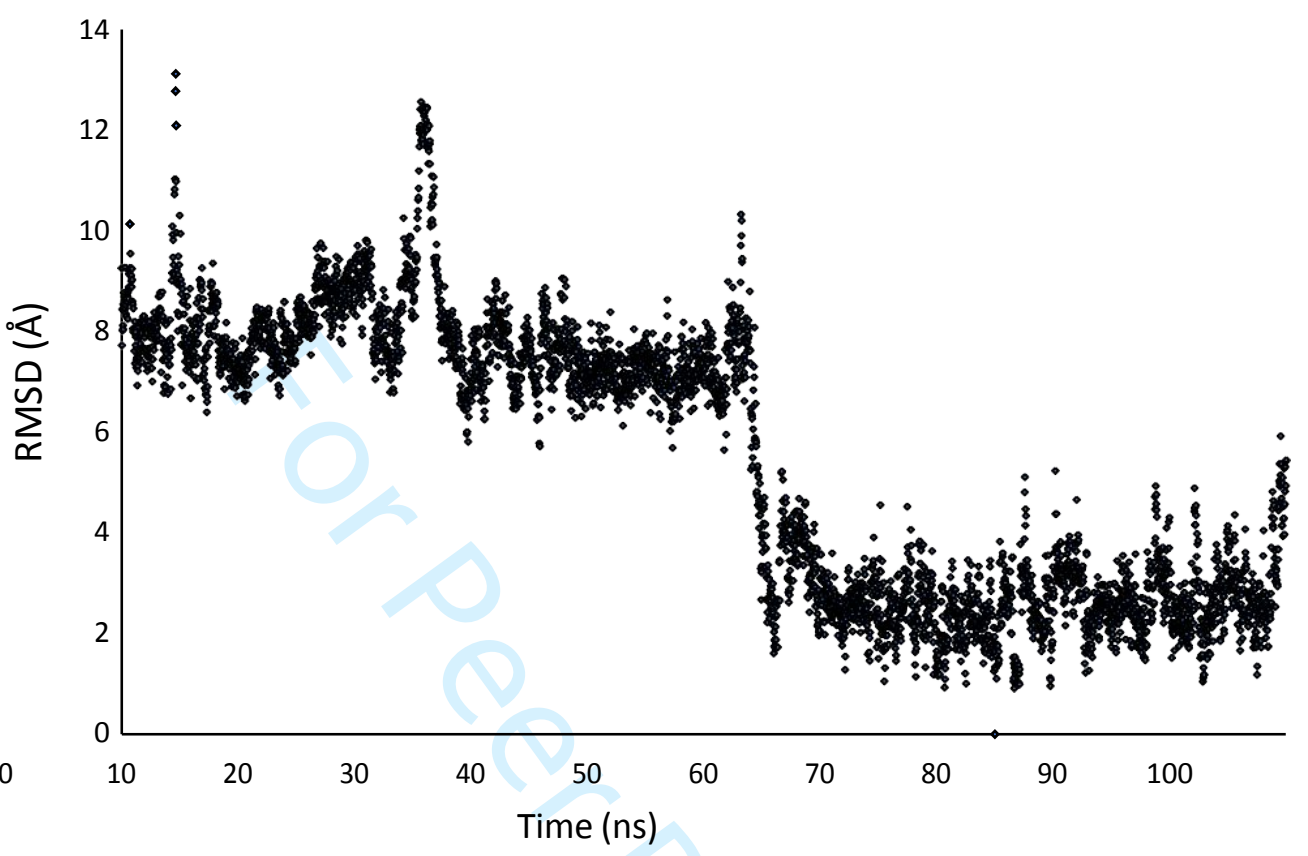

$\operatorname{RMSD}(\AA)$ of the fragment GCLRV throughout a 100 ns molecular dynamics simulation in complex with the receptor, referenced to the simulation frame at 75 ns. 


\section{Appendix 2}
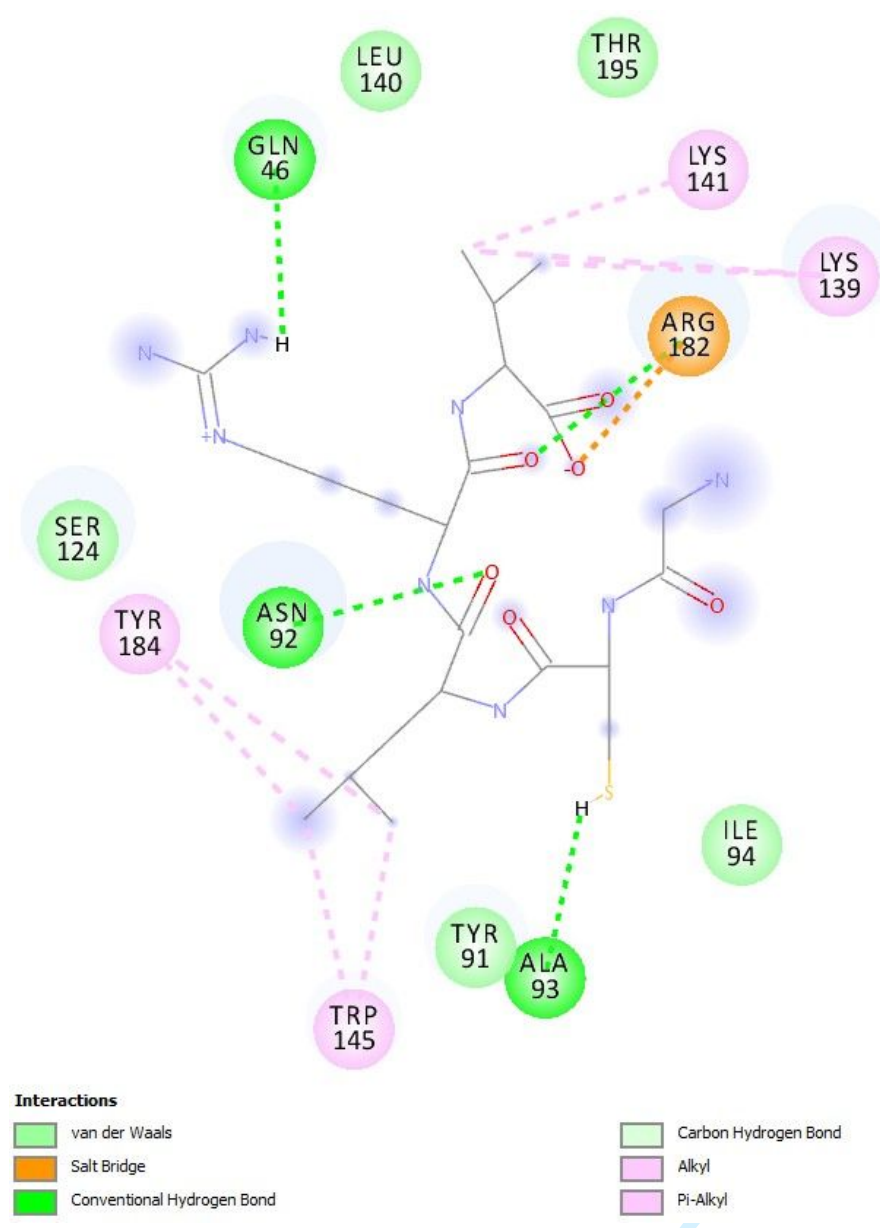

Two-dimensional view of the receptor-ligand interactions for GCLRV at $74 \mathrm{~ns}$ in the molecular dynamics simulation 


\section{Appendix 3}

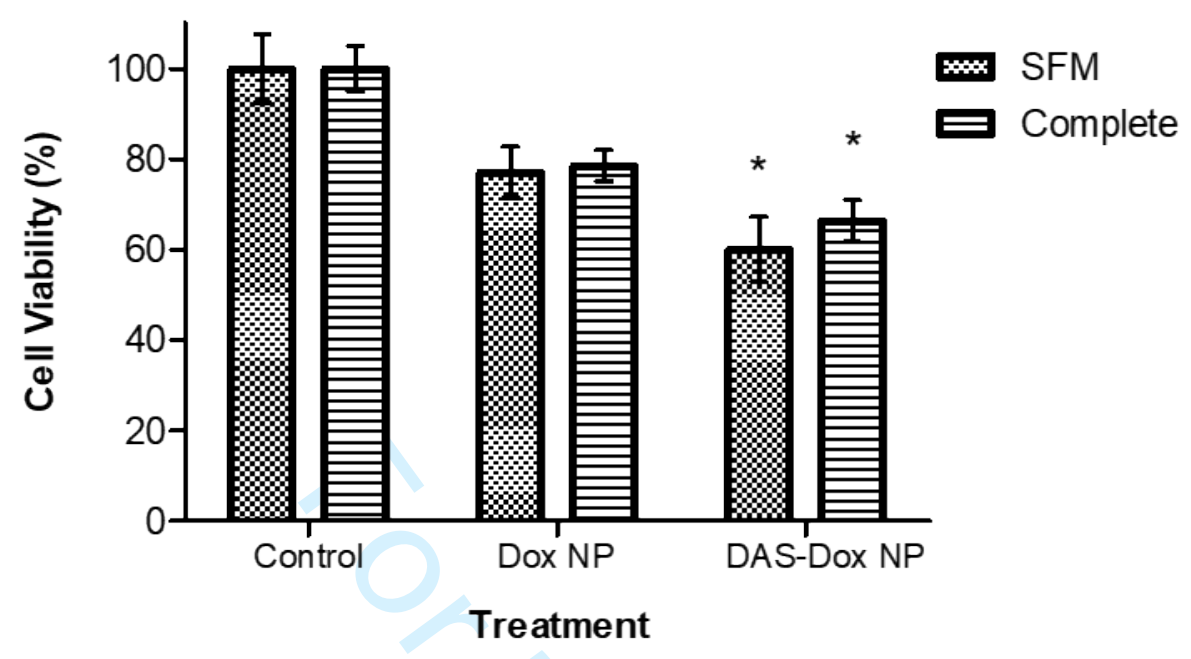

Cell viability of SH-SY5Y neuroblastoma cells following NP treatment in either serum-free medium (SFM) or with medium containing foetal bovine serum (complete). Control groups were treated with either SFM or complete media only. Cell toxicity was assessed by MTT assay following 24 hours of treatment at $37^{\circ} \mathrm{C}$. *Statistically significant difference compared to Dox NP treatment ( $P$ value $<0.05, n=6$ ). 


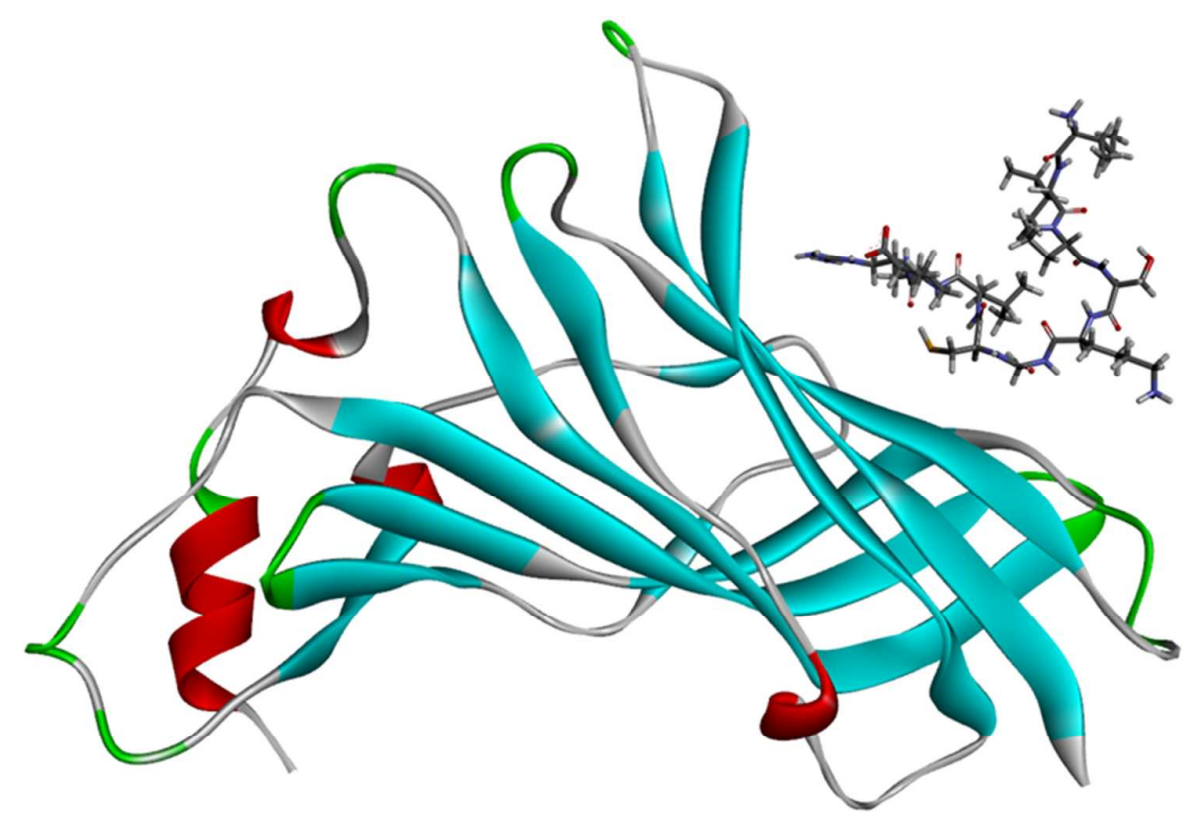

Figure 1. Snapshot at $92 \mathrm{~ns}$ from the molecular dynamics simulation of fragment IIPSKGCLRV (stick form) with the nicotinic acetylcholine receptor (ribbon form). Residues IIPS are not in contact with the receptor surface. 
Journal of Drug Targeting

Page 30 of 39

1

2

3

4

5

(A) Serum

6

7

8

9

10

11

12

13

14

15

16

17

18

19

20

21

22

23

24

25

26

27

28

29

30

31

32

33

34

35

36

37

38

39

40

41

42

43

44

45

46

47

48

49

50

51

52

53

54

55

56

57

(B) RDP- T=0

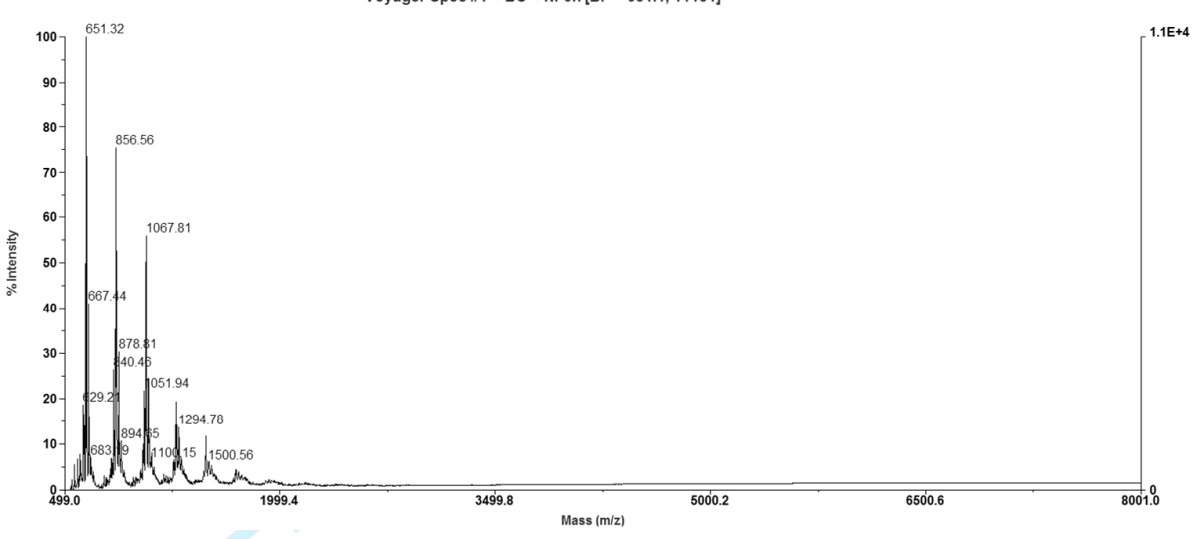

58

59

60

URL: http://mc.manuscriptcentral.com/gdrt Email: journaldrugtargeting@googlemail.com 
(D) RDP- T=8h

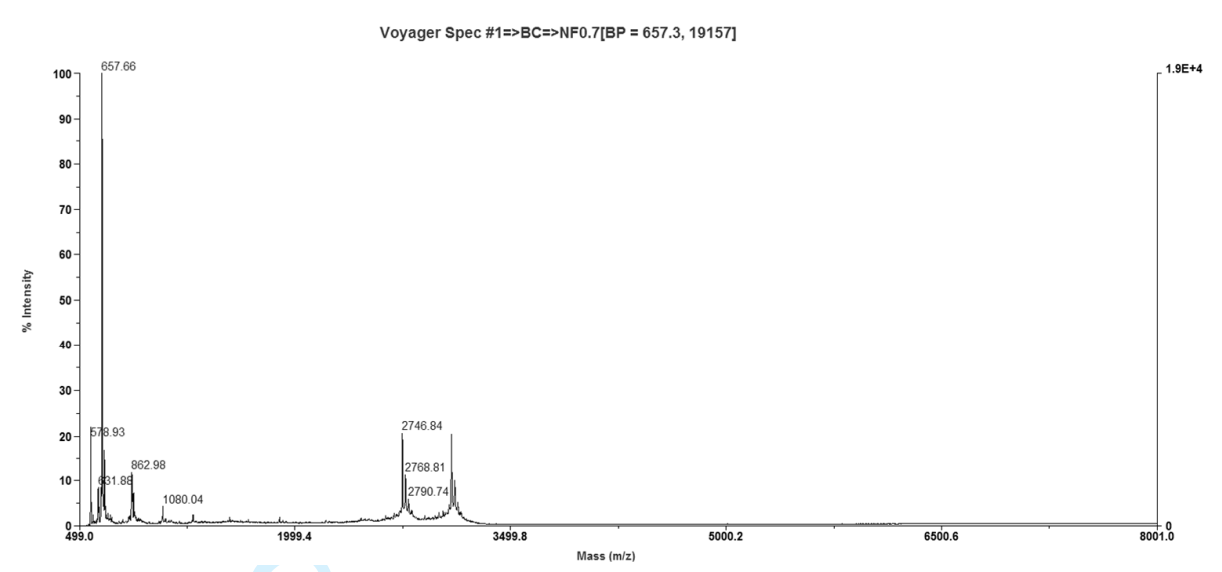

(E) DAS- T=0

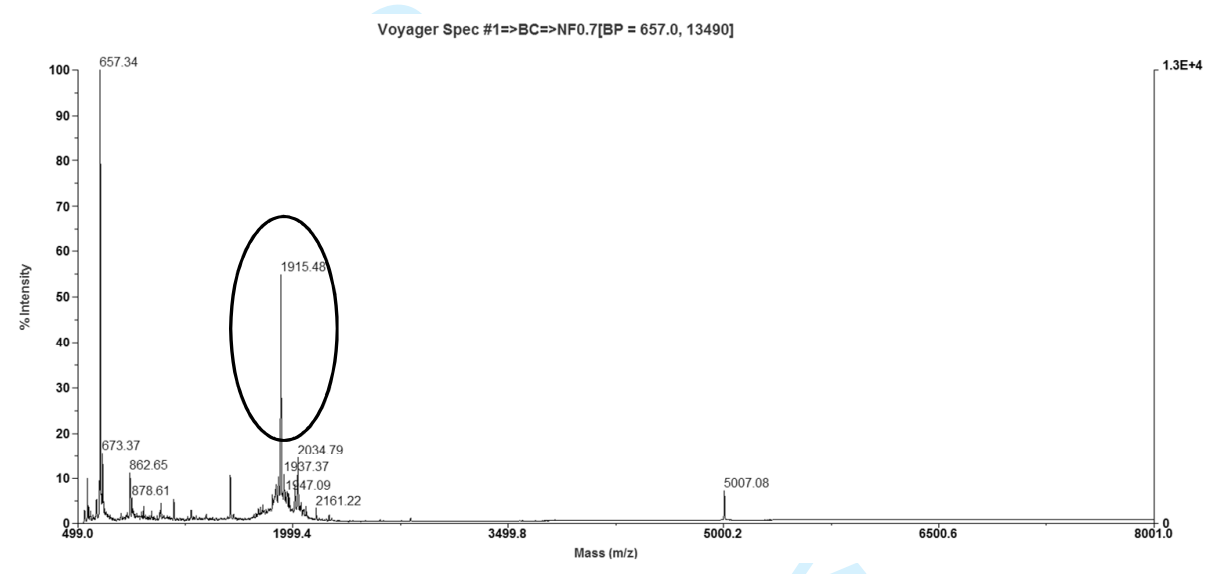

(F) DAS- T=2h

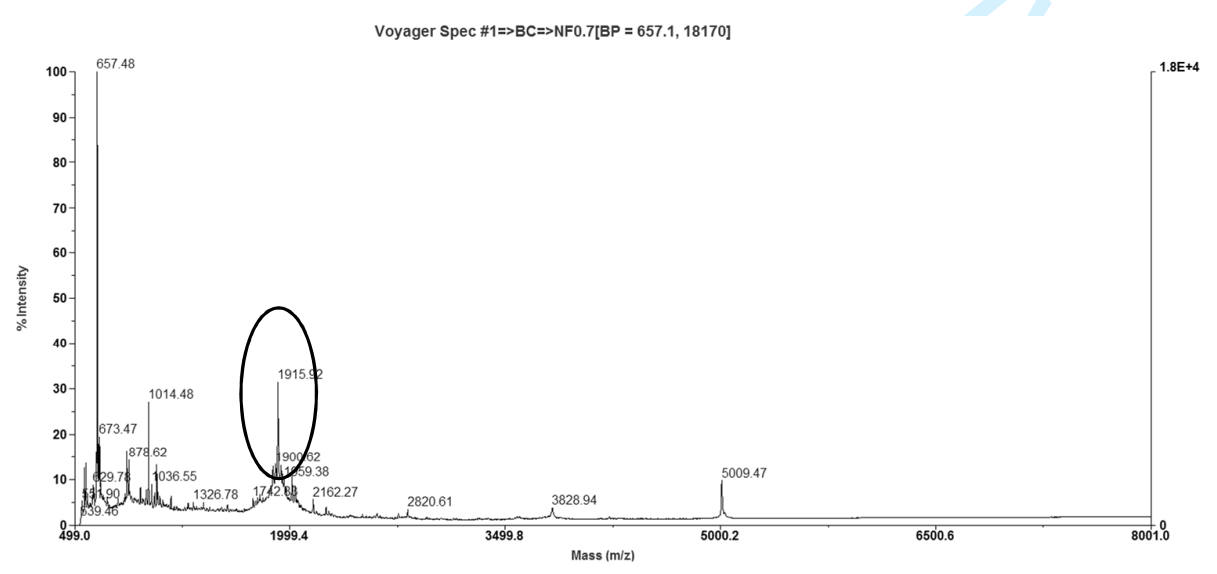

URL: http://mc.manuscriptcentral.com/gdrt Email: journaldrugtargeting@googlemail.com 
(G) DAS- T=8h

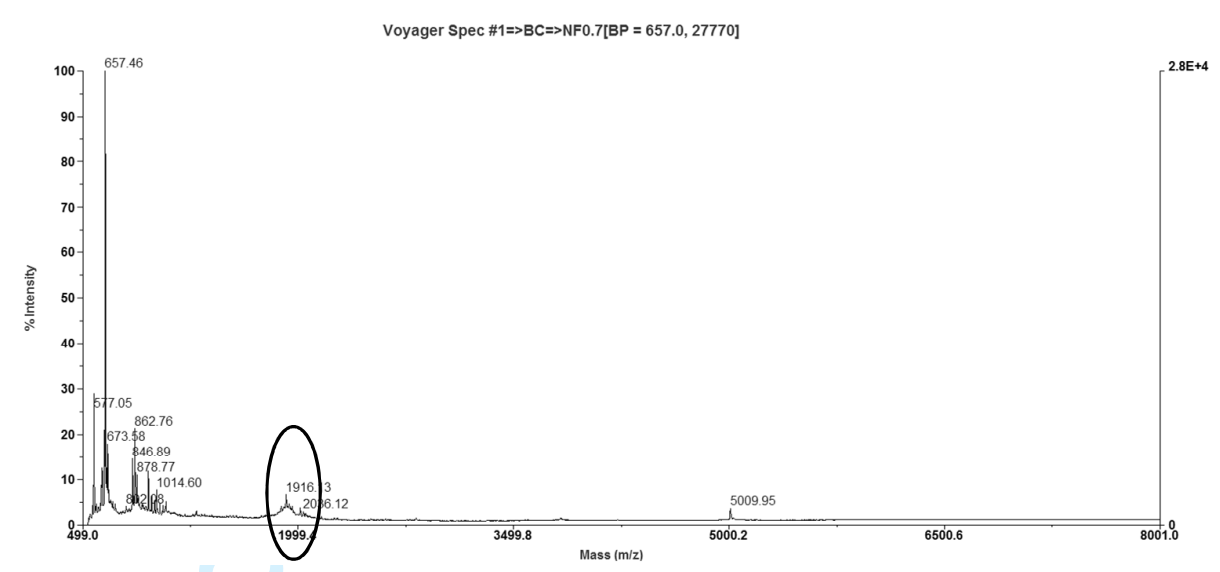

Figure 2. MALDI-TOF mass spectrometry analysis of peptide stability in $25 \%$ human serum at $37^{\circ} \mathrm{C}$ for various periods of time. (A) Human serum with no peptide. Profile detected for RDP (MW approx. 4.8kDa) in serum at time zero (B), 2 hours $(C)$ and 8 hours (D) post incubation. Peaks for intact peptide are indicated by a circle on the intensity/mass traces. DAS peaks (MW approx. $1.9 \mathrm{kDa}$ ) for the same time points are shown $(\mathrm{E})-(\mathrm{G})$ respectively. 
(A)

Lysotracker

FITC-Dextran

Control

$25 \mu \mathrm{m}$
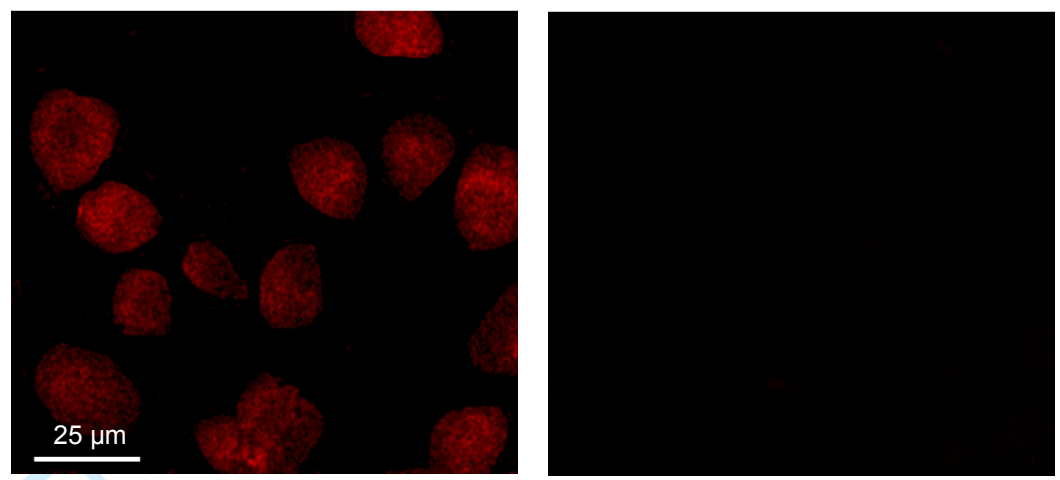

FITC-NP
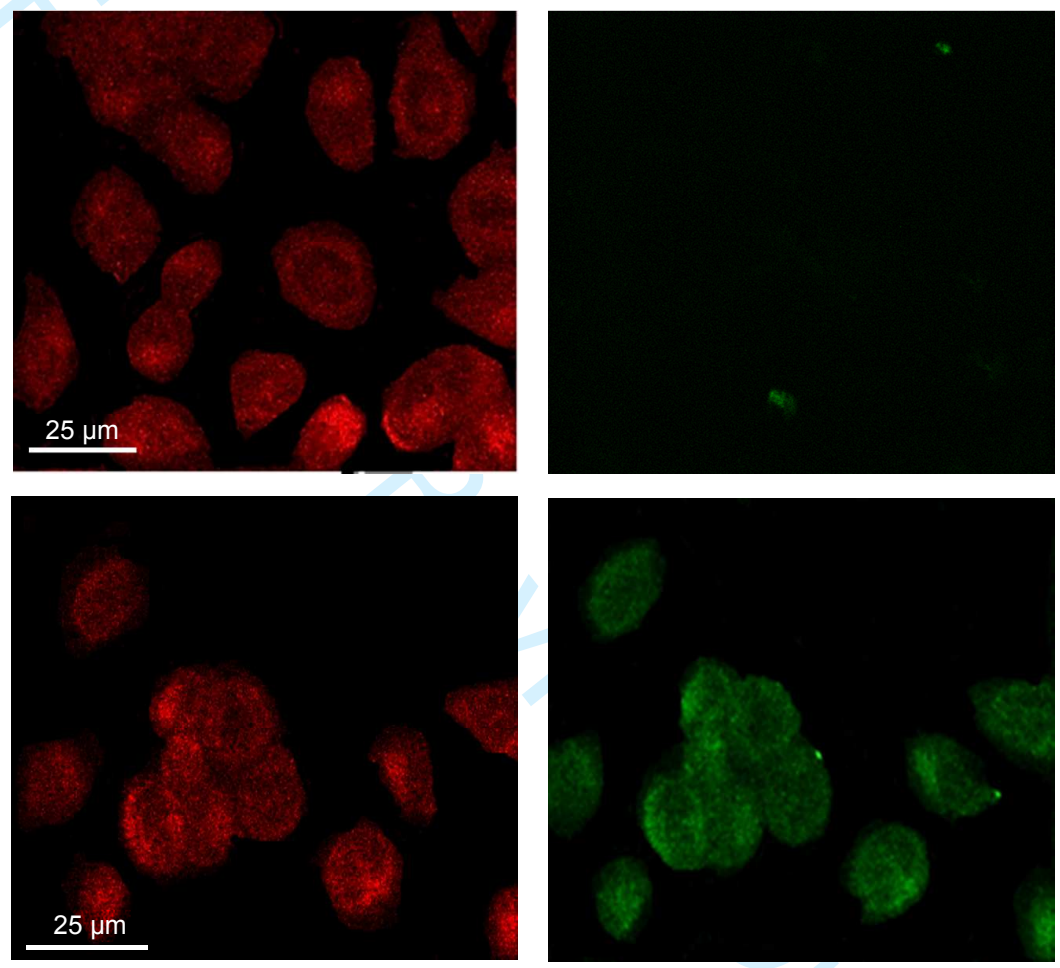

RDP-FITC NP
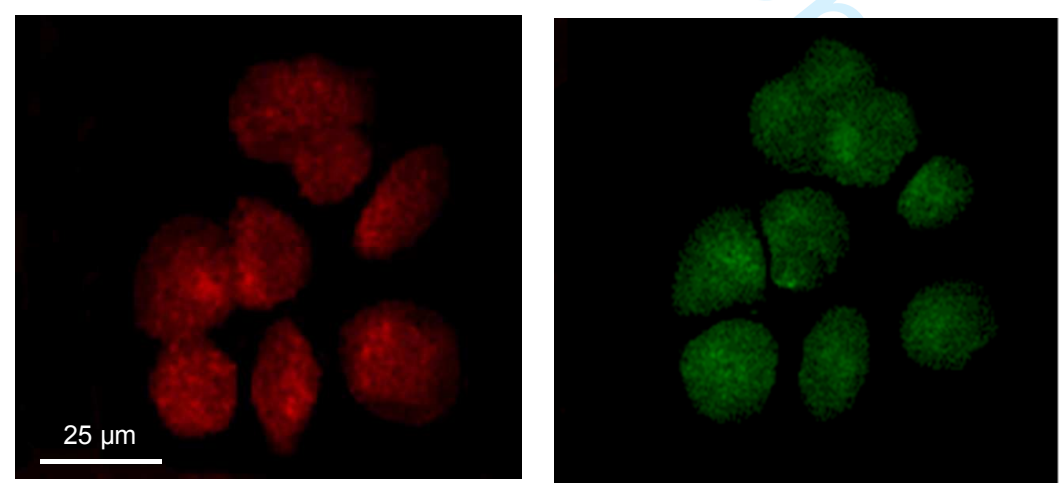

DAS-FITC NP

53

54

55

56

57 
(B)

Control

FITC-NP

RDP-FITC NP

DAS-FITC NP
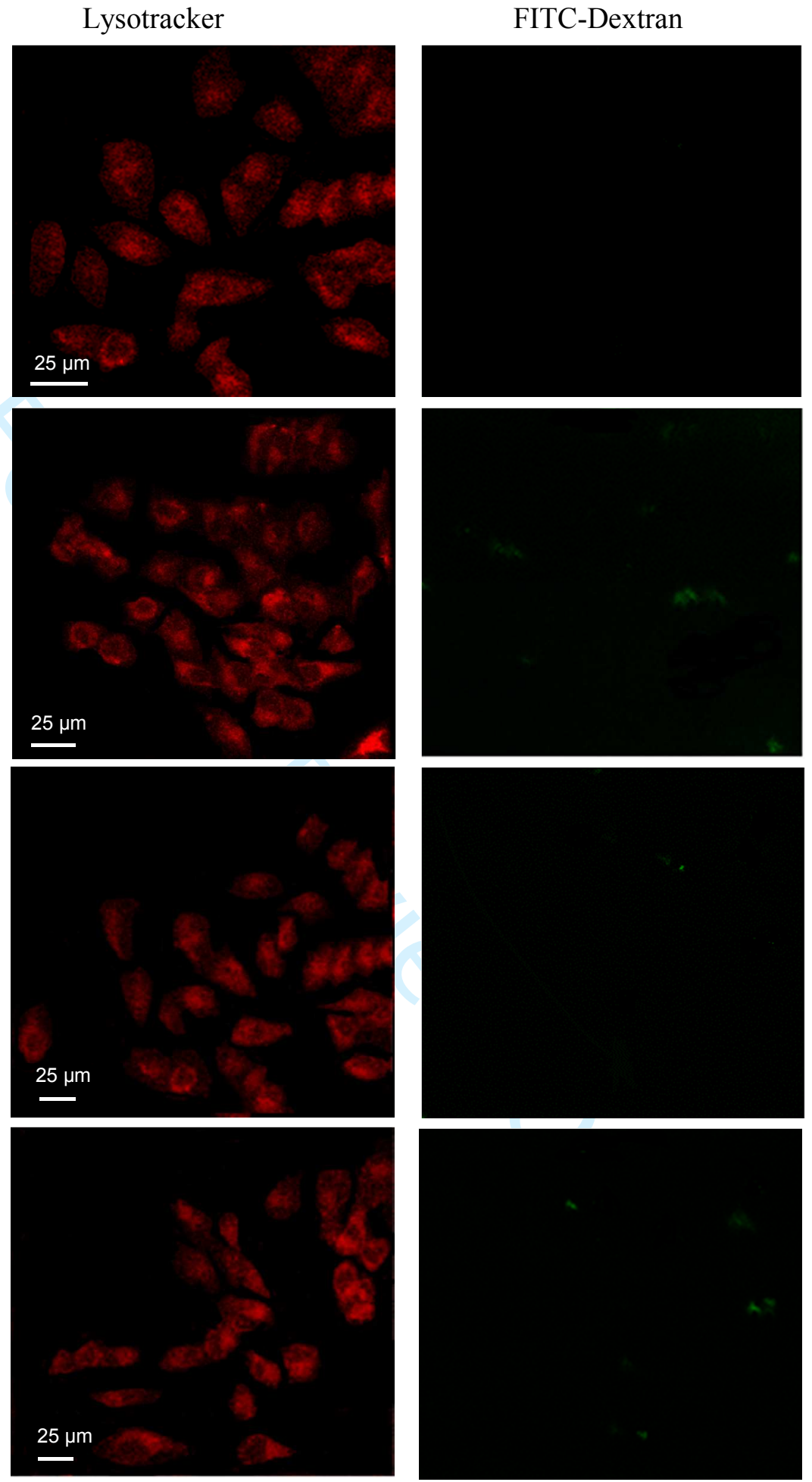

Figure 3. Confocal images showing the effect of RDP and DAS labelling on the cellular uptake of FITC-NP (green) in (A) SH-SY5Y cells and (B) HeLa cells. 
Page 35 of 39

Journal of Drug Targeting

$$
\begin{aligned}
& 1 \\
& 2 \\
& 3 \\
& 4 \\
& 5 \\
& 6 \\
& 7 \\
& 8 \\
& 9 \\
& 10 \\
& 11 \\
& 12 \\
& 13 \\
& 14 \\
& 15 \\
& 16 \\
& 17 \\
& 18 \\
& 19 \\
& 20 \\
& 21 \\
& 22 \\
& 23 \\
& 24 \\
& 25 \\
& 26 \\
& 27 \\
& 28 \\
& 29 \\
& 30 \\
& 31 \\
& 32 \\
& 33 \\
& 34 \\
& 35 \\
& 36 \\
& 37 \\
& 38 \\
& 39 \\
& 40 \\
& 41 \\
& 42 \\
& 43 \\
& 44 \\
& 45 \\
& 46 \\
& 47 \\
& 48 \\
& 49 \\
& 50 \\
& 51 \\
& 52 \\
& 53 \\
& 54 \\
& 55 \\
& 56 \\
& 57 \\
& 58 \\
& 59
\end{aligned}
$$

Concentration (mg/mL)

URL: http://mc.manuscriptcentral.com/gdrt Email: journaldrugtargeting@googlemail.com 
Figure 4. Determination of $\mathrm{IC}_{50}$ of DAS-DOX-NP on SHSY-5Y cells. 
(A)

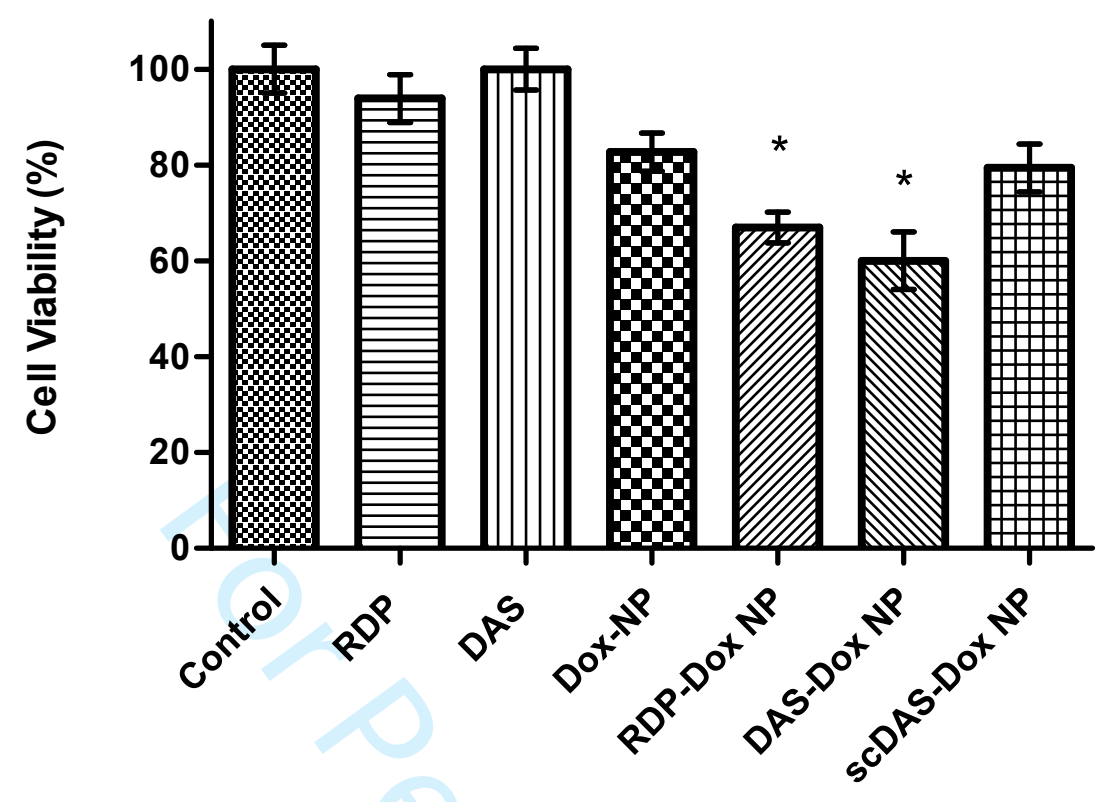

Treatment

(B)

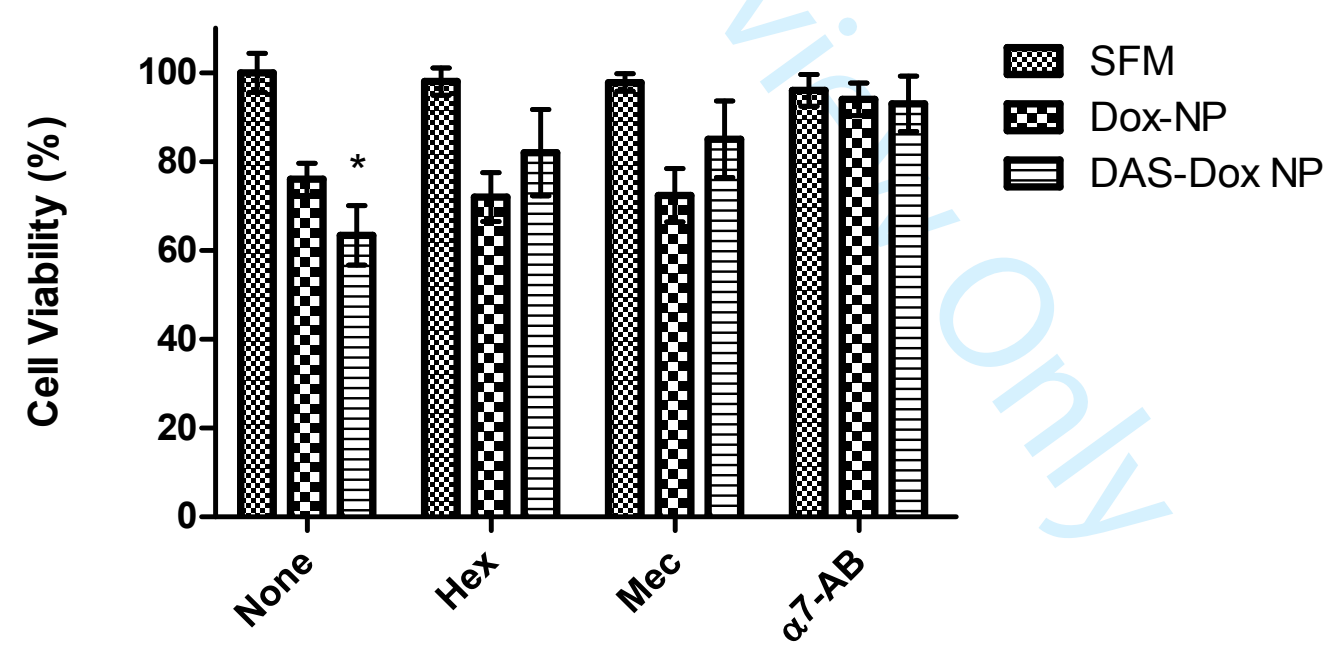

nAChR Inhibitor Treatment

Figure 5 4. SH-SY5Y human neuroblastoma cell viability following treatment with (A) DASconjugated doxorubicin-loaded NP (DAS-Dox NP) compared to free peptide and unlabelled doxorubicin NP (Dox-NP) and scrambled DAS NP. Control samples were treated with serum-free media only. (B) Effect of nAChR antagonists hexamethonium (Hex) and 
mecamylamine (Mec) and antibody directed against alpha-7 subunit of homomeric neuronal nAChR $(\alpha 7-\mathrm{AB})$ on DAS ligand activity on SH-SY5Y neural cells. * Statistically significant difference compared to Dox-NP (P value $<0.05)$. 


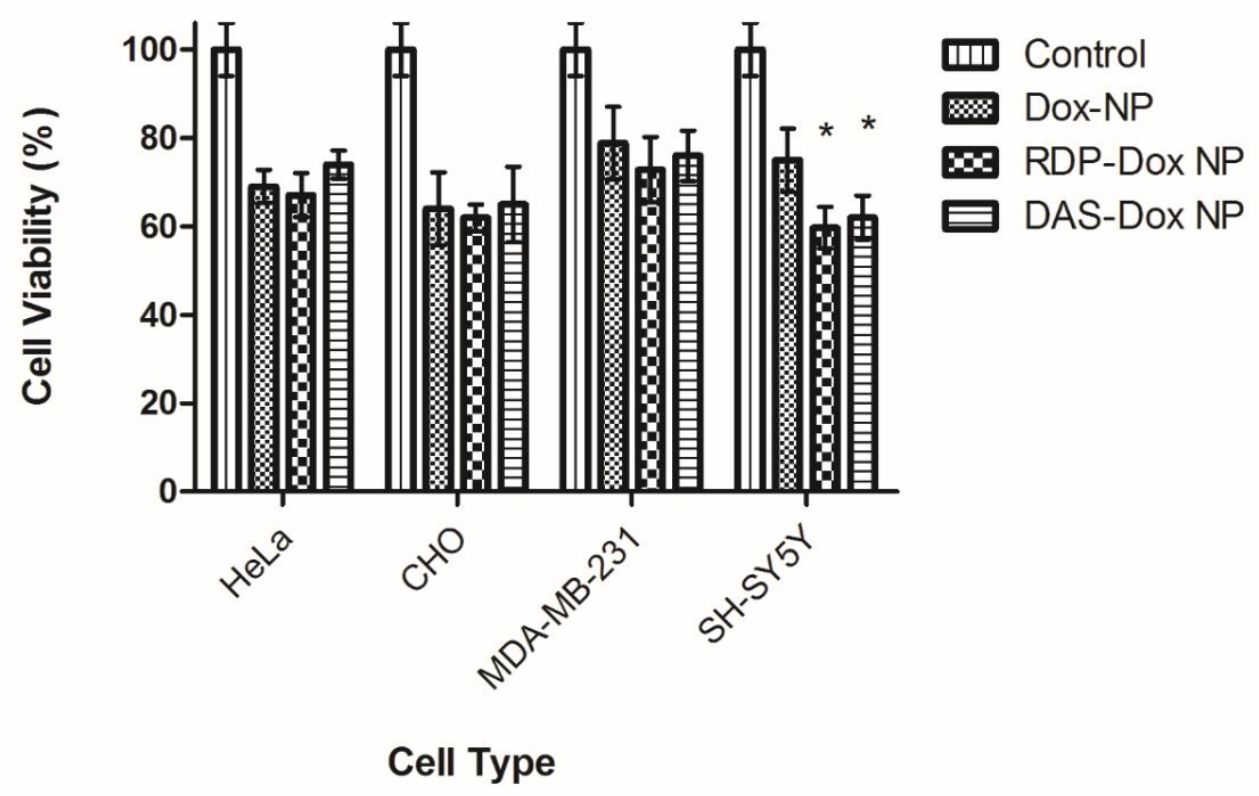

Figure $\underline{6}$ 5. Effect of peptide targeting ligands RDP and DAS on doxorubicin-loaded NP toxicity towards non-neural cell lines HeLa, CHO and MDA-MB-231 compared to SH-SY5Y neural cells. Control groups were treated with serum-free media only. * Statistically significant difference compared to Dox-NP (P value $<0.05)$. 